\title{
A Phase Ilb, randomized, multicenter study of the efficacy of GVAX pancreas vaccine and CRS-207 compared to chemotherapy or to CRS-207 alone in adults with previously-treated metastatic pancreatic adenocarcinoma (eclipse study)
}

\author{
Andrea Wang-Gillam ${ }^{1}$, Vincent Picozzi ${ }^{2}$, Todd Crocenzi ${ }^{3}$, Michael Morse $^{4}$, Herbert Zeh $^{5}$, Robert Fine ${ }^{6}$, \\ Aimee Murphy ${ }^{7}$, Justin Skoble ${ }^{7}$, Edward Lemmens ${ }^{7}$, Sandy Ferber ${ }^{7}$, Allan Rosen ${ }^{7}$, John Grous ${ }^{7}$, \\ Thomas W Dubensky ${ }^{7}$, Dirk Brockstedt ${ }^{7 *}$, Elizabeth Jaffee ${ }^{8}$, Dung Le ${ }^{8}$
}

From Society for Immunotherapy of Cancer 29th Annual Meeting National Harbor, MD, USA. 6-9 November 2014

\begin{abstract}
Background
A heterologous prime-boost vaccination strategy using GVAX pancreas vaccine and CRS-207 is showing promise in patients with metastatic pancreatic adenocarcinoma (PDA). GVAX is composed of lethally-irradiated, allogeneic pancreatic cancer cells modified to express GM-CSF and induces a broad response against multiple tumor antigens. GVAX is given with low-dose cyclophosphamide (CY) to inhibit regulatory T cells. CRS-207 is live-attenuated Listeria monocytogenes engineered to express the tumor-associated antigen mesothelin. CRS207 boosts responses against mesothelin and is unique in its capacity to stimulate both innate and adaptive immunity by activating $\mathrm{T}$ cells and NK cells. In a recently completed Phase II study, the CY/GVAX plus CRS-207 combination resulted in statistically-significant improvement of overall survival (OS) compared to $\mathrm{CY} /$ GVAX alone (Le, GI ASCO 2014).
\end{abstract}

\section{Methods}

This is a Phase IIb study comparing CY/GVAX and CRS207 to chemotherapy or to CRS-207 alone in adults with previously-treated metastatic PDA. Subjects will be enrolled in two cohorts: 150 subjects into a primary cohort of patients with at least two prior treatment regimens for metastatic disease $\left(3^{\text {rd }}+\right.$ line $)$ and 90 subjects into an exploratory cohort of patients with only one prior treatment regimen for metastatic disease $\left(2^{\text {nd }}\right.$ line). Subjects will be randomized in a 1:1:1 ratio to receive either 2 doses of CY/GVAX and 4 doses of CRS-207 (Arm A), 6 doses of CRS-207 (Arm B) or physician's choice of select single-agent chemotherapy (Arm C). The primary objective is to compare OS in the primary cohort between Arms A and C. Secondary/exploratory objectives include: comparison of OS in both primary and exploratory cohorts between all treatment arms, assessment of safety and clinical responses (tumor assessments and CA19-9 levels) and correlation of $\mathrm{Lm}$ - and mesothelin-specific $\mathrm{T}$ cell and other immunological responses with OS, progression-free survival and best overall response. (Sponsor: Aduro BioTech, Inc.; NCT02004262).

\begin{abstract}
Authors' details
'Washington University School of Medicine in St. Louis, St. Louis, MO, USA. ${ }^{2}$ Virginia Mason Medical Center, Seattle, WA, USA. ${ }^{3}$ Earle A. Chiles Research Institute, Portland, OR, USA. ${ }^{4}$ Duke University Medical Center, Durham, NC, USA. ${ }^{5}$ University of Pittsburgh Medical Center, Pittsburgh, PA, USA.

${ }^{6}$ Columbia University, New York, NY, USA. ${ }^{7}$ Aduro BioTech, Inc., Berkeley, CA, USA. ${ }^{8}$ The Sidney Kimmel Comprehensive Cancer Center at Johns Hopkins, Baltimore, MD, USA.
\end{abstract}

Published: 6 November 2014

${ }^{7}$ Aduro BioTech, Inc., Berkeley, CA, USA

Full list of author information is available at the end of the article 
doi:10.1186/2051-1426-2-S3-P68

Cite this article as: Wang-Gillam et al:: A Phase Ilb, randomized, multicenter study of the efficacy of GVAX pancreas vaccine and CRS207 compared to chemotherapy or to CRS-207 alone in adults with previously-treated metastatic pancreatic adenocarcinoma (eclipse study). Journal for ImmunoTherapy of Cancer 2014 2(Suppl 3):P68.

Submit your next manuscript to BioMed Central and take full advantage of:

- Convenient online submission

- Thorough peer review

- No space constraints or color figure charges

- Immediate publication on acceptance

- Inclusion in PubMed, CAS, Scopus and Google Scholar

- Research which is freely available for redistribution

Submit your manuscript at www.biomedcentral.com/submit 